\title{
Playfulness, ideology and the technology of conomat foolishness in the creation of a novel market niche for distributed control: The case of iPLON
}

\author{
Annachiara Casalini ${ }^{1}$, Guido Fioretti ${ }^{1 *}$ (D) and Andreas Pyka ${ }^{2}$
}

\section{* Correspondence:}

guido.fioretti@unibo.it

'University of Bologna, Bologna, Italy

Full list of author information is available at the end of the article

\begin{abstract}
Distributed control is a technology and a design philosophy that, albeit superior to centralized control, cannot spread because it would require restructuring existing industries. It survives, however, in specific market niches. In this case-study we report on a small firm creating a novel market niche for distributed control. It is an engineering firm, where commitment to a fascinating technology generates the ability to turn serendipitous encounters into business opportunities. Because of deep beliefs motivating people to commit their lives in spite of substantial difficulties, we speak of a technological ideology. We submit that, in this case, a technological ideology is key to explain the ability to explore novel possibilities, or the technology of foolishness according to James March.
\end{abstract}

Keywords: Technology of foolishness, Playfulness, Technological ideology, Distributed control, Internet of things, Market niche

\section{Background}

Technological breakthroughs, the invention of novel products, the creation of novel markets are increasingly important for advanced economies, and yet these processes are little understood. The prevailing attitude is that creativity cannot be investigated so it is wise to encapsulate it in a black box that no one attempts to open. This attitude allows innovation scholars to focus on issues that are more easily amenable to scientific research, such as technological paradigms or the diffusion of innovations.

Indeed, the serendipitous nature of creativity is apparently at odds with calculative rationality. At some point in time we realize that a novel product is there, a novel technology can be used and a novel market emerged and yet, all these novelties were not attained by means of careful evaluation of means and ends (March, 1978). Hence the attitude of relegating creativity in a corral in order to investigate what happens around it.

James March, a never-ending source of inspiration for organization studies, suggested quite a different attitude. While acknowledging that creativity cannot be understood within the usual framework, he suggested that it is not pure irrationality either. True, it is a weird decision process where goals and preferences, means and ends are conceived at the same time, but this process follows certain patterns nonetheless. Certain individuals

(C) 2016 The Author(s). Open Access This article is distributed under the terms of the Creative Commons Attribution 4.0 International License (http://creativecommons.org/licenses/by/4.0/), which permits unrestricted use, distribution, and reproduction in any medium, provided you give appropriate credit to the original author(s) and the source, provide a link to the Creative Commons license, and indicate if changes were made. 
and organizations are particularly good at it, and they possibly learned to be good at it. If it is foolishness, there exists a technology for managing it - hence his expression 'The Technology of Foolishness' (March, 1976) that appears in the title of our paper.

March suggested that the technology of foolishness can be grasped by looking at the attitude adults have towards children. Children do have goals, yet their goals change while growing up. For instance, newborns may pursue the goal of reaching objects whereas children in schooling age may pursue the goal of learning to compute. Adults do not regard the evolution of children's goals as serendipitous or irrational, but rather as a process where children progress towards ever better goals. Adults eventually set out to steer or facilitate this process, for instance by providing children with toys that stimulate their creativity, ranging from cubes to mechanical construction sets to children-friendly computer programming platforms. Creative play is the key to children's technology of foolishness, so adults consciously and rationally encourage it.

In this context, adult rationality is a means to achieve children creativity (March, 2006). An implication is, couldn't adults employ their rationality to foster their own creativity? Possibly, some individuals and some organizations do. And if they do, it makes sense for researchers to investigate how they do it. Improving adult playfulness is the aim of a technology of foolishness.

In this paper, we first set out to review the literature related to the technology of foolishness, including research that has been carried out without awareness of March's concept but that is clearly related to it. However, research on the technology of foolishness is in its infancy. It is still unclear which attitudes, cultures, emotions, behavioral rules or environmental stimuli prompt the ability to explore novel paths rather than exploit existing abilities. The available literature provides suggestions, theoretical frameworks, anecdotical evidence but only a few case-studies.

The main body of this paper is a case-study. Because of the explorative character of our knowledge in this domain, we think that an open-ended qualitative case-study can yield precious insights. We did not approach our case with a well-defined set of hypotheses to test. We rather started with certain expectations that we eventually modified in the course of our investigation. A section explains our methodology before expounding our findings.

Albeit we are aware that one cannot reach general conclusions by observing one single instance, we are convinced that careful observation of one empirical reality can shed light on what sort of research questions should be asked. In particular, our empirical case suggested a novel interpretive framework for looking at the technology of foolishness, namely, that an ideology - in our case, a technological ideology - can be one of its driving forces. In the section devoted to our case-study we subsume and discuss our findings with the aid of key interview excerpts. A final section concludes.

\section{Literature review}

The expression 'technology of foolishness' may suggest irrationality, but it is the quintessence of rationality in fact (Izak, 2013). It's about extending the reach of rationality up to include the pursuit of discovery, the search for novelty driven by the awareness that all we know about the future is that it will be different from anything we might expect. We identified nine streams of literature that relate to the technology of foolishness, even if not all of them mentioned it. 
1. The technology of foolishness is what tells us when it's the case to carry out exploration instead of exploitation, another well-known distinction made by James March (1991). Thus, the first stream of literature that relates to the technology of foolishness is precisely that large area of research pointing to the fact that, in a variety of situations, lack of perspectives, dwindling though not (yet) exhausted resources, or danger however perceived trigger exploration (Cyert and March, 1963; March and Shapira, 1987, 1992; Døjbak Håkonsson et al., 2016). Also in our case-study we could observe that a crisis that triggered playful exploration. However, not all firms that are in trouble carry out exploration, so other factors must operate as well.

2. A second stream of literature focuses on what managerial actions are most conducive to exploration. Support for risk-taking, tolerance of mistakes, leaders' support for innovators, insulation of creative people from the more bureaucratic structures are the typical recommendations of this literature (Sutton, 2001; Caldwell and O'Reilly III, 2003; Mendonca and Rao, 2008), which eventually expands into the concept of ambidextery, i.e., the ability to carry out both exploration and exploitation (Tushman and O'Reilly III, 1996; O'Reilly III, Harreld and Tushman, 2009; O'Reilly III and Tushman, 2011, 2013). Albeit managerial action enabling exploration certainly pertains to the technology of foolishness, it is not the focus of this paper. We are rather concerned with the attitudes of those who do carry out exploration, possibly with managerial support but essentially out of their own initiative. In any case, our case-study concerns a firm too small for its actions to be constrained by bureaucratic rules.

3. Thirdly, psychological literature on team creativity and innovation can be taken as pertaining, or at least tangent to the technology of foolishness. This literature peaked in the 1990s but it has been sharply criticized thereafter for providing a rather mechanistic picture of innovation processes (McAdam and McClelland, 2002; Anderson, De Dreu and Nijstadt, 2004). Its main findings concern the impact of factors such as team diversity, members interdependence, team size, longevity, vision, participation, support for innovation, task orientation, cohesion, internal/ external communication and conflict on innovation, ultimately finding that 'vision', 'task orientation' and 'external communication' are the strongest determinants of innovative capability (Hülsheger, Salgado and Anderson, 2009). One may relate these findings to the above literature on managerial actions fostering exploration, but the concepts employed by this psychological literature are even more generic than those of the managerial one. At any rate, we did not find that any of these concepts would be useful in order to understand our case-study.

4. A fourth stream of research stresses the importance of quickly embarking in practical action rather than theorizing, developing theory out of experience and letting reality open your mind. Since this line of thought is meant as a guideline for exploration, it definitely pertains to the technology of foolishness. It is a possibly wide stream of heterogeneous researches, of which we list just the few we are aware of. First of all Sarasvathy and Dew (2005), which is the only investigation where March's 'technology of foolishness' is explicitely mentioned. In this paper, the authors constrast a sample of entrepreneurs to a sample of MBA students and, furthermore, they interview the actors involved in the development RFID 
(Radio Frequency IDentification) tags. They stress that innovative entrepreneurs make choices based on their sense of identity, enter practical action rather than embarking in detailed evaluation of consequences, and actively seek stable and trusted relations. The second member of our collection is Schrage's investigation of the roles of prototypes in innovation (Schrage, 2000). Here the main point is that prototypes make people interact, discuss issues, suggest novel perspectives and help people create solutions. Building prototypes, including computer-based virtual prototypes, is one technology that we use in order to keep some foolishness in adult life. The third and last element of our heterogeneous collection is the usage of Role Playing Games (RPGs) and Agent-Based Models (ABMs) in order to stimulate creative agreements within social groups that must share natural resources (Barreteau et al., 2003). Also in this case, techniques such as RPGs and ABMs are employed in order to make people discuss and explore possibilities for novel solutions. Heterogeneous as they are, these example show that experimenting with action is an important ingredient of the technology of foolishness.

5. A fifth, related stream of research, concerns the serendipitous character of innovation. While serendipity is not contemplated by most theories of decision making, the Garbage Can model of organizational choice (Cohen, March and Olsen, 1972; Fioretti and Lomi, 2010) stands out as a paramount exception. In this model, 'solutions' exist independently of decision-makers who eventually discover them by serendipitous, random encounter. Being prepared to serendipitous discovery is an important element of the technology of foolishness. The invention Post-it note pads is a good point in case (Nayak and Ketteringham, 1994), but serendipitous discoveries occurred also in our case-study.

6. The discovery of innovation networks, first in biotech and subsequently in other industries, provided insights that we can subsume as a sixth stream of research relevant for the technology of foolishness. Several researchers remarked that networking positively affects a firm's ability to innovate (Gemünden, Ritter and Heydebreck, 1996; Ritter and Gemünden, 2003, 2004; Pittaway et al., 2004). Insofar certain sorts of networking stimulate exploration, they also pertain to the technology of foolishness and indeed, we also found remarkable networking abilities by the firm that we investigated.

7. The seventh stream of research was suggested by March himself (1976), who linked the technology of foolishness to the ability to re-interpret history, creating a coherent narrative that, at the cost of distorting the past, enables novel, unconventional decisions to be made in the present. The very topic of the plasticity of the past was initiated by March and Olsen (Cohen and March, 1974; March and Olsen, 1976; Olsen, 1976), to be eventually continued by Weick $(1979,1995)$ and lately Lane and Maxfield (2005) on a case-study that is closely related to ours. It is not unique to organization science (Hobsbawm and Ranger, 1983), although it is particularly effective in order to explain organizational behavior. Since the ability to construct a coherent narrative is key to elaborating a vision, we agree that it is very relevant for the technology of foolishness albeit we did not find it in our case-study.

8. The eight stream entails those accounts of extreme innovativeness that are fostered and sustained by some ethos, shared values or ideologies (Plowman et al., 2007; 
Mendonca and Sutton, 2008). Psychologically, such findings are rooted in concepts of determination and self-efficacy (Bandura, 1993; Duckworth et al., 2007). We shall see that, in our case-study, this aspect is extremely important.

9. Finally, psychological research has stressed that a technology of foolishness can be embedded in specific tools that are employed in order to stimulate playfulness. These tools can be as diverse as virtual reality where organization members interact through avatars (Dodgson, Gann and Phillips, 2013), or toy bricks with which a 3D-model of organizations are constructed (Jacobs and Statler, 2014). However, no such tools were employed in our case-study.

\section{Case presentation}

We investigated a firm that makes use of a novel technology, distributed control. This technology is their prime mover and, as we shall say, it is a sort of technical ideology. It plays a key role in this firm's technology of foolishness, so it is appropriate that we explain what it is. This section is made of two subsection: first a subsection on distributed control, then a subsection introducing the firm that we investigated.

\section{Distributed control}

In 1988 Mike Markkula, a co-founder of AppIe Computers, founded a new company in Silicon Valley called Echelon. Echelon designed the Neuron, a microchip that could be embedded in physical devices which, in their turn, would be connected to one another through a Local Operating Network (LON). Echelon would sell the Neuron and the LonTalk communication protocol, which together made up the LonWorks control technology (Lane and Maxfield, 2005, 2009).

LonWorks was an early instance of the so-called "Internet of Things". Since the microchips embedded in different devices would communicate with one another, these devices would provide functions that neither could exhibit in isolation. For example, an occupancy sensor, a light switch and a thermostat could regulate the lighting and temperature of a room as soon as someone entered it. Or, an alarm clock could wake someone up but also send a message to a coffee machine making it brew a cup of coffee. Other applications may range from the automation of large buildings to agile productive plants, power plants networks or any other setting where a large number of heterogeneous devices must coordinate their operations while retaining some flexibility.

The architecture designed by Echelon was radically different from the leading technological paradigm of that time. According to received wisdom sensors and actuators would be wired through a hierarchical set of data hubs, which would route all information towards a central computer that would execute operations and issue appropriate commands back to local devices. By contrast, Echelon set out to implement a distributed control architecture. Each device would be endowed with its own microchip, and each device would be able to communicate with any other.

Distributed control is technically superior to centralized control. Its advantages are due to $(i)$ system scalability, in the sense that devices can be added or taken away without re-programming the whole system, and (ii) reliability in front of power shortages, for several microchips working in parallel take a much shorter time to restore normal operations. From a purely technical point of view, there was no doubt that distributed control would superseed centralized control. 
Markkula regarded distributed control as a forthcoming major revolution in information technologies. In the previous two decades, computer architectures had moved from centralized proprietary mainframe computers to decentralized proprietary minicomputers, and subsequently to personal computers interconnected over large peer-topeer networks. Since the underlying hardware and software technologies for control systems were similar to those of computer systems, it was sensible to think that the control industry would evolve along a similar path (Wired, 1993).

However, distributed control provides its largest benefits if a large number of heterogeneous devices are connected, and these devices are eventually produced by different firms. Each of these firms has an interest in connecting its own devices by means of a distributed architecture, but none of them is happy to see distributed networks where devices from different vendors compete with one another. Each big producer prefers to stipulate agreements where only its own line of products are used, and each big producer typically adds any sort of technical difficulty to impair its devices from communicating with those of its competitors. Thus, we are experiencing the paradoxical reality of a superior technology which is technically available since the end of the 1980s, but which has not been allowed to spread in the economy hitherto (Rossi et al., 2009).

Distributed control did not spread, but it did not disappear either. Rather, it survived and diffused in specific market niches. Echelon obviously occupied most of these niches, but other firms were also able to find unexpected usages. The ensuing section tells the story of the creation of a novel market niche by a small installer of Echelon's microchips.

\section{A system integrator}

Echelon used to have - and still has - two sorts of customers (Lane and Maxfield, 2005). On the one hand, the original equipment manufacturers (OEMs) who embed the Neuron microchip in their devices. On the other hand the so-called 'system integrators', i.e., small firms that would attach the Neuron microchip to devices of any sort and any make, realizing distributed control solutions tailored to specific problems. Typically, OEMs are large and established firms that dominate several markets. By contrast, system integrators are small firms with a fascinating but hard and adventurous life, always looking for novel applications for which they have to design specific solutions.

We interviewed one of these firms, iPLON. The reason for focusing on this particular firm is that, at a certain point of its life, $i P L O N$ was able to escape from its uncertain life as a system integrator by creating a novel market niche for distributed control, where it subsequently specialized. This jump testifies of a rare ability to explore novelties.

The founder of $i P L O N$, Mr. Victor Thamburaj, graduated in 1972 from the Indian Institute of Technology Madras. He quickly moved to Germany in order to work for Bosch but in 1975 he left Bosch for ZIEHL Industrie-Elektronik GmbH and, soon afterwards, THEN Dye Machines where he worked for over twenty years as a control systems engineer. In $1997 \mathrm{Mr}$. Thamburaj left THEN in order to found T-LON (later on, $i P L O N)$, a system integrator that would apply Echelon's LonWorks technology. In subsequent years T-LON/iPLON eventually integrated LonTalk with other communication protocols, such as the IP open protocol, but it remained focused on distributed control.

Since its foundation $i P L O N$ is located in Schwäbisch Hall, in the south-western German region of Baden-Württemberg. In 2007, ten years after its foundation, iPLON 
started to apply distributed control to photovoltaic panels (PVPs). This quickly became its main business, the market niche that it created and where it specialized. In 2011 iPLON opened a subsidiary in Chennai, in the Indian state of Tamil Nadu. The Indian subsidiary works only with the distributed control of photovoltaic panels whereas the Schwäbisch Hall mother company still engages in other projects. On the whole $i P L O N$ is still a small firm, with 15 employees in Schwäbisch Hall and 20 employees in Chennai.

\section{Methodology}

From 2002 to 2005 the EU-funded ISCOM $^{1}$ project at the University of Modena and Reggio Emilia (Lane, Pumain and Van der Leeuw, 2009) investigated, among else, the diffusion of distributed control in Europe. Researchers participated to professional meetings and interviewed 50 main actors in Europe, publishing a report where two actors were described in detail: one was $E N E L$, a large Italian electricity provider that adopted Echelon-powered meters, while the other one was T-LON/iPLON (Rossi et al., 2009). The reasons behind the choice of $i P L O N$ were that (i) it was a paramount example of a creative and inventive system integrator, and that (ii) it was attempting to create networks with local authorities and other system integrators that apparently transfered the philosophy of distributed control into the social realm. None of us participated to the ISCOM project, but we have been granted access to all of its documentation including the 2003 interview to T-LON/iPLON's Victor Thamburaj.

At a more than 10 years distance, we asked ourselves what happened to this remarkable system integrator. We observed from its web site that it had created a novel market niche for distributed control, namely PVPs. We found this was intriguing so we arranged a follow-up research where one of us (AC) visited both the Schwäbisch-Hall (Germany) and the Chennai (India) sites, making interviews and accessing $i P L O N$ documents.

Given what we knew about $i P L O N$, we had expectations regarding:

a) Serendipitous discovery/creation of a new market niche for distributed control, namely PVPs. In the literature review, we mentioned this as the fifth stream of research relevant for the technology of foolishness. Because of our surprise to discover that the system integrator that was considered most interesting in 2003 (Rossi et al., 2009) was also one that created a novel market niche, this was an obvious choice.

b) Networking abilities. In our literature review we mentioned that a stream of research points to the ability to network with other social actors as a good predictor of a firm's innovativeness, which we labelled as the sixth stream of literature relevant for the technology of foolishness. Since in 2003 T-LON/iPLON was found to be particularly engaged with networking both with other system integrators and at the local political level (Rossi et al., 2009), we expected it to be still doing so.

c) The ability to re-interpret history is the only ingredient of the technology of foolishness that was extensively mentioned by March himself (March, 1976). In our literature review, we referred to this as the seventh stream. Since T-LON/iPLON changed its role from a generic system integrator to a main actor in a small market niche, we expected some change to have taken place with respect to what Rossi et al. found (Rossi et al., 2009). 
With the basic framework of Classic Grounded Theory in mind (Glaser and Strauss, 1967; Orton, 1997), we were prepared to see reality overthrowing our expectations which actually happened, as the next section will make clear. We conducted open-ended interviews where our expectations were reflected by questions regarding: (a) How it happened that the market niche was discovered, where we did our best to evince serendipitous happenings; (b) Relations to other system integrators, to competitors and to local institutions; (c) Their vision for the future and their understanding of the past, both for themselves and for the whole industry of distributed control. However, we also allowed our interviewees to speak freely about the issues they found most interesting, which most often happened as a consequence of questions (c).

We interviewed chief programmer Thomas Kurz (Jan 29 $9^{\text {th }}$ 2015), CTO Edgar Schneider (Jan $20^{\text {th }}$ and Jan $29^{\text {th }}, 2015$ ) and CEO Victor Thamburaj (Feb $21^{\text {st }}$ and Aug $\left.31^{\text {st }}, 2015\right)$. Furthermore, we were granted access to the ISCOM unpublished interview to Victor Thamburaj made by Paolo Gurisatti in 2003. The second interviews to CTO Schneider and CEO Thamburaj were made in order to clarify or deepen specific issues, which was not necessary in the case of Thomas Kurz. All interviews were recorded. Their analysis made clear that no further interview was necessary.

The three interviewees exhaustively represent the organization we have been investigating. Edgar Schneider used to work with Thamburaj at THEN and followed him when he founded $i P L O N$ (then $T-L O N$ ) in 1997. Thomas Kurz joined them shortly afterwards. These three people have been the main decision-makers at T-LON/iPLON since its beginnings, and still are.

Insofar we were looking for the issues (a), (b) and (c) above, we applied pre-conceived qualitative data analysis that either confirmed or disconfirmed our expectations by finding or not finding incidents that were coherent with them. However, questioning about (c) led our informants to speak about their identities and passions, and this made us arrange concepts into new theoretical constructs as Classical Grounded Theory prescribes (Glaser, 2002; Glaser and Holton, 2004). In particular, we found that the most relevant, innovative and surprising attitudes of our informants could be first subsumed under three categories that we labeled 'Vision and Group Cohesion', 'Identity' and 'Adventurous Life' (of system integrators), respectively. Subsequently, we arranged them within a concept of a 'technological ideology' that we eventually related to the stream of literature labeled as the n. 8, which included case studies such as Mozilla/Firefox (Mendonca and Sutton, 2008) where the ideology of free software provided a stream of volunteers who were free to pursue novel ideas, and a Church (Plowman et al., 2007) where pastors determined to apply evangelical precepts opened their premises to homeless people and, by doing so, attracted an increasing number of novel members. We made the most significant excerpts of our interviews available, either in appendices or within boxes in the next section.

\section{Findings}

The first of our expectations, the item (a), was that the novel market niche was discovered out of serendipitous occurrences that our interviewees were able to turn into a business opportunity. We did find this and, strictly intertwined with serendipity, we also found that the loss of a big customer was quite important for them in order to start looking for serendipitous events. In the terms of our literature review, we found incidents supporting 
stream n. 5 (serendipity) intertwined with incidents supporting stream n. 1 (danger triggers exploration).

Most importantly, when pressed for details our interviewees told us stories that were superficially made of chains of fortuitous events, but actually entailed also the ability to exploit these events. Among the ingredients of this ability, the social skills of Mr. Thamburaj was prominent. Social skills are quite unusual for technically-oriented people, but it was even more remarkable that the other two interviewees, also technically-oriented people, were able to appreciate the importance of these skills for business. To some extent, serendipitous events are not independent of networking abilities as in literature stream n. 6.

We also remarked that our interviewees' description of how they arrived at creating the market niche was similar to their description of the way they arrived at a novel customer - e.g., a producer of automated coffee machines - at the time they were still a pure system integrator. This was a first hint that the experience gained as a system integrator was crucial for $i P L O N$ 's technology of foolishness. Appendix 1 entails key excerpts relevant to (a).

Given our previous knowledge of T-LON/iPLON coming from the ISCOM project, we expected $i P L O N$ to exhibit strong networking abilities. This, we labelled expectation (b). Networking abilities are exclusively related to the stream of literature n. 6.

We found out that the networking initiative mentioned by Rossi et al. (2009), Infranet Valley, was no longer operative. However, we identified two active initiatives in $i P L O N$ 's networking activities. The first one, Infranet Partners, dates back to its beginning as a system integrator: It is a network of companies employing the LonWorks technology. The more recent one, which iPLON labels The Post-Carbon Society, is a vision of businesses, institutional and social actors engaged in the construction of a more "green" economy. Since $i P L O N$ started to specialize in photovoltaic panels its engagement with Infranet Partners has been fading away, essentially because technical problems repeat themselves at each new installation so peers are less needed for help. By contrast, its commitment to The Post-Carbon Society is on the rise and very visible to the public. For instance, a main company brochure (iPLON 2015a) is devoted to The Post-Carbon Society and only in the heading $i P L O N$ describes itself as 'The Infranet Company.' Appendix 2 entails key interview excerpts on Infranet Partners and The Post-Carbon Society, respectively.

We also had expectations (c) that $i P L O N$, having re-focused its activities to PVPs, would have re-interpreted its own history accordingly. Our expectation was reinforced by the fact that March himself (1976) pointed to the importance of this attitude for the technology of foolishness, initiating a whole stream of literature that we subsumed under the heading n. 7. Our expectations had a concrete possibility to be checked, for we could compare the interview made by P. Gurisatti in 2003 within the ISCOM project to our own interviews.

We did not find any evidence concerning the re-interpretation of the past. This company has its root in the technology of distributed control, and this root did not need to be changed in order to move into solar energy. One may argue that limiting distributed control to PVPs could be perceived as a reduction of the original dream of attaching microchips to nearly all electrical devices, but on the other hand the vision of The PostCarbon Society may have contributed to keep the original élan alive. For instance, a 
main company brochure where $i P L O N$ illustrates its expertise (iPLON 2015b) starts with PVPs but continues with seven other projects in entirely different domains. This does not diminish the importance of March's intuition; simply, re-writing the past was not necessary in this case.

However, the questions suggested by (c) were extremely important because they allowed our interviewees to speak about what was most important for them: distributed control, its technical superiority, its prospects, the difficult relations with OEMs, their lives as system integrators, the dream of a more stable business based on PVPs. On these issues our informants spoke with a passion that - we realized - was a prime mover of their technology of foolishness. We allowed our interviewees to speak freely on what was most important for them.

We first gathered the ensuing incidents in three categories:

- Vision and Cohesion. It was immediately clear that we were dealing with passionate, visionary people. This firm was founded out of a deep understanding of distributed control and its technical potentialities, and cohesion within the founding group came along with this commitment. Appreciation of the technical potentialities of distributed control was key for the grit and determination of our interviewees. We gathered a few representative statements in Tables 1, 2 and 3.

- The Identity. This firm is a system integrator. System integrators are proud of connecting devices of different producers in order to exploit all the potentialities of distributed control. They understand their identity in opposition to OEMs who embed microchips in their devices but, by hampering communication with the devices produced by their competitors, they do not allow distributed control to display its capabilities. By contrast, system integrators are proud of exploring all potentialities of distributed control.

Table 1 Vision and cohesion

Twenty years ago, a new technology called LonWorks came into the market. It was completely based on decentralized solutions and I liked that technology very much. We started experimenting it for the control system of a machine, after the first results... I decided to open a company 'cause I thought that decentralized electronic systems were the future. The potential of this technology was not clear right in the beginning (...). Twenty years ago we were not sure where this technology would have led us, but in the same time it was an innovation where smaller companies can get into. Only after a couple of years I realized how strong the product was and also how many things were still missing: that's why I thought it was a challenge for smaller companies to proceed and try to make a project over it. (Victor Thamburaj, 2015)

I started in iPLON right from the beginning, I have founded the company together with Mr. Thamburaj and three more people. The starting point was that I had worked together with Mr. Thamburaj in a company called THEN. They were making dyeing machines; we had contact with LonWorks technology there. Before they had PLC systems (...) then we made tests with all the systems and we found the LonWorks technology: from the beginning we have realized that this very new technology had much more possibilities than the others, so we decided to use it. (...) I know Mr. Thamburaj 'cause he lives close to my place, so we had met outside the company. Mr. Thamburaj is a smart guy, he convinced me to start with this company.

We had the vision that we could solve a lot of the problems we were facing with this new technology. (...) We had this vision. When we started we didn't know if it would have really worked, but we had the vision it could be possible. (Edgar Schneider, 2015)

I was in a company manufacturing test equipment, for example (...) kitchen equipment [as well as all] kind of industrial automation equipment. (...) I was there from 1995 to 1997, so a bit more than three years, and we wanted to decentralize automation (...). [While] evaluating different technologies (...) we also came into contact with $P$ PLON, and (...) the engineers decided for the LonWorks system. [They] said it's the best. (...) And so I left that company, I stayed with the technology which I considered to be best and changed to IPLON. (Thomas Kurz, 2015) 
Table 2 The identity

The strength of the LonWorks technology is to connect different devices from different manufacturers. What we have seen - for example in the building automation, where LonWorks is very commonly used - is that there are a lot of big players [the OEMs]. They are using the LonWorks technology but they are not open. They always try to make their own specific pieces, and these devices can only talk to... [mentions one OEM] devices, for instance. They claim to be open in using LonWorks technology, but they are not. The problem is that these big players have the strength to do this because they have a lot of the market. So, for the small companies there's the problem to put the idea of interoperability in this market. (...) In this way, system integrators can't easily use parts from different manufacturers.

(Edgar Schneider, 2015)

They have the possibility to make everything: from developing devices to developing the software to control them and also the installation (...), so they can do the whole solution with their own products. But this is not the idea behind LonWorks, behind this technology: the basic idea is that you can use different parts, different devices, from different manufacturers and put them together to make the best solution for the end customer. (Edgar Schneider, 2015)

- An Adventurous Life. Systems integrators conduct an adventurous life. They do not have a fixed set of customers, and each new customer poses a novel problem calling for a creative solution. True, the creation of a market niche brought stability to iPLON, but the company's culture has been shaped through years when it had to look for novel fields of activity all the time.

These categories are related to one another. We propose to subsume them under the term technological ideology, meaning a system of beliefs that informs and orients behavior with respect to - in this case - founding a firm, creating and pursuing a vision, and being sufficiently foolish to play with opportunities and novelties.

Of course, ideologies can either open new interpretive frameworks or blind the human mind to truth, and it is quite likely that both effects are there at the same time, all the times. In our case, a technological ideology based on distributed control was the engine prompting enthusiastic engineers to find novel usages for it. However, the same ideology could act as a brake if, one day, a technological breakthrough brings in a still better technology that makes distributed control obsolete.

We found that technological ideologies, or more in general ideologies, systems of values and beliefs are a neglected topic in the tiny literature on the technology of foolishness, but we also found out that a few case-studies deal with its importance for innovation. ${ }^{2}$ One of them (Mendonca and Sutton, 2008) is based on another technological ideology, that of free software, which prompted fundamental organizational and

Table 3 An adventurous life 
strategic changes in writing computer code and even suggested extensions of its mode of operation into other domains, e.g., crowd-funding. The other example (Plowman et al., 2007) is a religious ideology centered about putting evangelical values into practice, which made pastors aware of the needs of a neglected category of people and, by mobilizing action, enabled them to rescue their Church from decay. These and possibly many other cases - of which we are unaware - suggested us to create what we denoted as the n. 8 stream of research relevant for the technology of foolishness.

Ideologies can stultify the human mind but, if taken with a bit of salt, they can rejuvenate sober adults into playful children looking for novelties. In this respect, we would like to make a final remark on iPLON. Already the 2003 interview (Rossi et al., 2009) made clear that T-LON/iPLON was not making exclusive usage of Echelon's LonWorks; already at that time, the open IP communication protocol was also used. When we observed this firm in 2015 this process had gone still further, as the change of name into iPLON testifies. What did not change was the enthusiasm and belief in the technological concept, namely, distributed control. This attitude, in our opinion, testifies of a creative, inventive and mind-opening usage of a technological ideology.

\section{Conclusions}

Mankind has always been aware of the importance of exploring novel possibilities. Curiosity and open-mindedness have always been associated with intelligence. Dicta such as "Wisdom is knowing not to know" (Socrates) or "Stay hungry, stay foolish!" (Steve Jobs) testify how widespread this conviction is. The distinguishing feature of March's position is that the exploration of novel possibilities can be managed through deliberate cultivation of some degree of foolishness and playfulness.

A technology of foolishness is not irrationality, and it is not behavior out of control. It is a decision technology, in the sense that it is a set of procedures that can be consciously enacted in order to become more easily aware of novelties and more prone to valuing them.

The literature on the technology of foolishness or, more widely, on the determinants of exploration, is scarce and sparse. We contributed to it with a case-study that highlights the power of certain deep beliefs to motivate people while keeping their minds awake, young and playful. We used the word 'ideology' because a belief in the value and prospects of distributed control, in spite of all difficulties and setbacks encountered by this technology since its inception, has more to do with passions and value systems than individualistic calculation of personal interests. Ideologies provide theoretical frameworks to make sense of reality, suggesting causal relations and a vision for the future that sparks action and enthusiasm. In this sense, an ideology can be one major ingredient of a technology of foolishness.

We are aware that ideologies can equally well stultify human beings, and that for this reason they eventually carry a negative connotation. We are aware that ideologies can impair exploration and destroy that very technology of foolishness that they were supposed to support. Yet this did not happen in the case we studied.

The notion of technological ideology is possibly new, yet social movements such as free software should make us aware of their existence and importance for business. In principle we should expect technological ideologies to be subject to the same pros and 
cons of any other form of ideology, though a more optimistic stance may speculate that, since technological ideologies are more easily subject to performance measurement and falsification than other ideologies, they are also less liable to be turned into means for thought control. This is difficult to assess because technological ideologies concern the passions of engineers and other technicians and, to our knowledge, these passions have been little studied hitherto.

There may be something to gain from the study of technological ideologies. Top management is overwhelmingly concerned with legal, financial and social networking issues, but the ultimate source of a firm's competitiveness most often lies with its mastery of technologies. Awareness of technological ideologies may make a difference when it comes to hire technical personnel and, most importantly, make it work sufficiently foolishly.

\section{Endnotes}

${ }^{1}$ ISCOM: Information Society as a COMplex system. Start date: 01/09/2002. End date: 31/08/2005. Project Number: IST-2001-35505. Funded within FP5-FET STREP projects. Principal Investigator: David A. Lane.

${ }^{2}$ We wish to express our gratitude to an anonymous reviewer for pointing to these case-studies.

\section{Appendix 1}

Interview Excerpts Relative to Expectation (a)

We started with solar technology in 2007. The reason for it, it was that we had had some problems with some big customers, we had made some developments together but then, they decided to make the development on their own, they also had the possibility to do the hardware development on their own, so we lost them. In 2007 we had the need to find new business, it was also the time when the solar market in Germany started, so we made some trials to see how it could work and we also found some local companies. We had a lot of discussions about how the business seemed and what solutions were available. We presented to these companies the solution of LonWorks technology, explaining how it could be useful for their business. One of these main customers was the local utility company of Schwäbisch Hall, we had a good cooperation with them, so we started to put our technology in that field.

(Edgar Schneider, 2015)

I think that there was some customer we lost. We were looking for new projects and I don't know who gave us this contact but the Landkreis [a local government body], they decided to establish an office to (...) do public consulting for renewable energy. So they had people who want to build a house, and told them you can go to this company to get solutions (...). At the same time there came (...) this renewable energy door in Germany, (...) and then the people from the Landkreis, they thought, why not finance our consulting this way? So they said, we put money into PVPs and the money which we get back, we put into this renewable energy consulting. (...) this was the first time when in our environment somebody asked for a monitoring system. And we had done monitoring systems at this time in totally different area, in cleaner rooms (...) we came into contact 
with them, they asked: "Couldn't you give us offer for monitoring PVPs?" So at once, we were looking for projects, we had already experience with monitoring, they asked for a monitoring system for PVPS.

(...) How did we come in contact with them? (...) You met Mr. Thamburaj? [Interviewer: "Not yet."] He's well known in this region. Everybody knows the guy from India living here. Since 30 years, 40 years he's playing tennis, football (...), and so many people know him.

(...) Today we are not expecting so much money from marketing, but at that time... (...) For example we sponsored a menu in a pizza restaurant (...). We make such actions. So around Schwäbisch Hall people (...) knew that there is an innovative company which is flexible and has a technology nobody understands but it's decentralized (...).

(Thomas Kurz, 2015)

Sometimes, when you see a chance to get some business, when you see you have a good opportunity to make something, you pick it. But it is not like a real "decision", it is not like "Now we are going to the security doors market". Sometimes there were personal relations between us and people of other companies, we saw that we could work together, that the developers had good relationships to each other,... so we started to make a small development together and then we saw it could work and they decided to use us, our communication parts for all their devices. But it was by chance, a step by step development. We didn't say: "this is the market we want to go to". (...) When we worked for the coffee machines company, the first contact came up by chance: we have had a colleague - from THEN - he had left THEN some years ago and he had started at this coffee machines company. His job was to decide a new, totally new, coffee machine. They wanted a new machine. He had to interface different systems. Then, this guy remembered my colleagues and me, he remembered that we always have done communication things, different protocol implementations, communication between devices,... so he remembered that we had some background in this area. He gave us a call and he says "I have a problem: I have different parts that should communicate, what are your ideas to solve it?" So I mentioned to him: "Have a look at this technology, it could fit your needs". Then he sent us a requirement of this coffee machine, we had a look on it and we sorted a kind of study out of it. With this study we had convinced his company to do this development with our technology.

(Edgar Schneider, 2015)

\section{Appendix 2}

\section{Interview Excerpts Relative to Expectation (b)}

There's something we have implemented, we called it Infranet Partners, it is a community of 6 or 7 companies in Europe, all companies are like iPLON: small companies which develop solutions based on LonWorks technology. But each company has its own strengths: iPLON is mostly doing industrial solutions, other companies operate in building automation, lighting applications,... We are different partners with different skills but all based on LonWorks technology. (...) we have not any contract. We are all small companies, we know every employees, we don't need formal relationships. We organize meeting, we are trying to meet at least once a year. Normally it starts with everybody 
talking about new projects, new developments, what their company is doing, what's developments they are using, what are the needs in that specific market,... You can get an idea of what they are doing, so you can see if these developments are also useful for your application, for what you are doing. Afterwards we also do specific projects we develop together. We are trying to only have one company in each country, we don't want to have direct competitors. Our meeting are not open but just for partners, so we can talk freely. (...) I think it started because at the beginning we did a lot of exhibitions, we met each other and we put up this network. Now it is different: we are doing other exhibitions, not the basic LonWorks exhibitions, mostly exhibitions which are focused on renewable energy.

(Edgar Schneider, 2015)

(...) We have started a project with KfW-DEG [KfW is a German Government-owned development bank; DEG is its subsidiary for developing countries], a bank in Germany that is assisting iPLON to bring renewable energy to Tamil Nadu. Tamil Nadu is almost as big as Germany, so we have to start de-central at the local level. So Musiri became the ideal place where in the rural area which iPLON could start. That's why Musiri is the first implementation of the so-called "Post Carbon Society" which is on the roadmap of iPLON. This happened because in the last six months (...) iPLON's biggest customer has set up 200 MegaWatt of (...) solar plants [in Musiri].

(Victor Thamburaj, 2015)

\section{Acknowledgements}

Annachiara Casalini received a students' mobility grant from the University of Bologna (Forlì campus) in order to spend 1 month in Germany. This grant was assigned by means of the call 2750-2014. We wish to thank Paolo Gurisatti for making his 2003 interview to Victor Thamburaj available to us.

\section{Authors' contributions}

AC wrote her MsC Thesis on the firm IPLON under the supervision of GF. AC spent 1 month in Germany in order to carry out the interviews. During this month she was hosted at Andreas Pyka's institute. AP carries out research on innovation and took great interest in AC thesis. AC later spent 1 month in India in order to complete acquaintance with IPLON. GF wrote the final manuscript, which has been approved by the other authors. Authors have been listed in alphabetical order.

\section{Competing interests}

The authors declare that they have no competing interests.

\section{Author details}

${ }^{1}$ University of Bologna, Bologna, Italy. ${ }^{2}$ University of Hohenheim, Hohenheim, Germany.

Received: 26 March 2016 Accepted: 15 September 2016

Published online: 27 September 2016

\section{References}

Anderson N, De Dreu CAW, Nijstadt BA (2004) The Routinization of Innovation Research: A constructively critical review of the state-of-the-science. J Organ Behav 25:147-173

Barreteau O et al. (2003) Our Companion Modelling Approach. J Artif Soc Social Simul, 6. Available at <http://jasss.soc. surrey.ac.uk/6/2/1.html>. Accessed on 18/03/2016.

Bandura A (1993) Perceived Self-Efficacy in Cognitive Development and Functioning. Educational Psychologist, 28:117-148. Caldwell DF, O'Reilly CA III (2003) The Determinants of Team-Based Innovations in Organizations: The role of social influence. Small Group Res 34:497-517

Cohen MD, March JG (1974) Leadership and Ambiguity: The American College President. McGraw-Hill, New York

Cohen MD, March JG, Olsen JP (1972) A Garbage Can Model of Organizational Choice. Adm Sci Q 17:1-25

Cyert RM, March JG (1963) A Behavioral Theory of the Firm. Prentice-Hall, Englewood Cliffs

Dodgson M, Gann DM, Phillips N (2013) Organizational Learning and the Technology of Foolishness: The Case of Virtual Worlds at IBM. Organ Sci 24:1358-1376

Døjbak Håkonsson D, Kjær Eskildsen J, Argote L, Mønster D, Burton RM, Obel B (2016) Exploration Versus Exploitation: Emotions and Performance as Antecedents and Consequences of Team Decisions. Strateg Manag J 37:985-1001

Duckworth AL, Matthews MD, Kelly DR, Peterson C (2007) Grit: Perseverance and Passion for Long-Term Goals. Journal of Personality and Social Psychology, 92:1087-1101. 
Fioretti G, Lomi A (2010) Passing the Buck in the Garbage Can Model of Organizational Choice. Comput Math Organ Theory 16:113-143

Gemünden HG, Ritter T, Heydebreck P (1996) Network Configuration and Innovation Success: An empirical analysis in German high-tech industries. Int J Res Mark 13:449-462

Glaser BG (2002) Conceptualization: On theory and theorizing using grounded theory. Int J Qual Methods 1:23-38

Glaser BG, Holton I (2004) Remodeling Grounded Theory. Grounded Theory Rev 4:1-24

Glaser BG, Strauss AL (1967) The Discovery of Grounded Theory. Aldine Transaction, New Brunswick

Hobsbawm E, Ranger T (eds) (1983) The Invention of Traditions. Cambridge University Press, Cambridge

Hülsheger UR, Salgado JF, Anderson N (2009) Team-Level Predictors of Innovation at Work: A comprehensive meta-analysis spanning three decades of research. J Appl Psychol 94:1128-1145

iPLON (2015a) Energy, Environment, Social Responsibility. Company Brochure

iPLON (2015b) Overview: The iPLON Story, Technologies and Applications, iPLON in Solar. Company Brochure

Izak M (2013) The Foolishness of Wisdom: Towards an inclusive approach to wisdom in organization. Scand J Manag 29:108-115

Jacobs CD, Statler M (2014) Toward a Technology of Foolishness: Developing Scenarios Through Serious Play. Int Stud Manage Organ 36:77-92

Lane DA, Maxfield RR (2005) Ontological Uncertainty and Innovation. J Evol Econ 15:3-50

Lane DA, Maxfield RR (2009) Building a New Market System: Effective action, redirection and generative relationships. In D. Lane, S. van der Leeuw, D. Pumain, G. West (eds.), Complexity Perspectives in Innovation and Social Change. Springer, Berlin-Heidelberg, Ch.IX, pp. 263-288

Lane DA, Pumaine D, Van der Leeuw S (2009) Introduction. In: Lane DA, van der Leeuw S, Pumain D, West G (eds) Complexity Perspectives in Innovation and Social Change. Springer Verlag, Berlin-Heidelberg

March JG (1976) The Technology of Foolishness. In March, JG, Olsen JP (eds.), Ambiguity and Choice in Organizations. Universitetsforlaget, Bergen. Reprinted (1988) in March JG (ed.), Decisions and Organizations. Basil Blackwell, Oxford

March JG (1978) Bounded Rationality, Ambiguity, and the Engineering of Choice. Bell J Econ 9:587-608

March JG (1991) Exploration and Exploitation in Organizational Learning. Organ Sci 2:71-87

March JG (2006) Rationality, Foolishness, and Adaptive Intelligence. Strateg Manag J 27:201-214

March JG, Olsen JP (1976) Organizational Learning and the Ambiguity of the Past. In: March JG, Olsen JP (eds) Ambiguity and Choice in Organizations. Universitetsforlaget, Bergen

March JG, Shapira Z (1987) Managerial Perspectives on Risk and Risk Taking. Manag Sci 33:1404-1418

March JG, Shapira Z (1992) Variable Risk Preferences and the Focus of Attention. Psychol Rev 99:172-183

McAdam R, McClelland J (2002) Individual and Team-Based Idea Generation Within Innovation Management: Organisational and research agendas. Eur J Innov Manag 5:86-97

Mendonca LT, Rao H (2008) Lessons from Innovation's Front Lines: An interview with IDEO's CEO. McKinsey Q 2008:1-7 Nayak PR, Ketteringham JM (1994) Breakthroughs! Pfeiffer \& Co, San Diego

Olsen JP (1976) The Process of Interpreting Organizational History. In: March JG, Olsen JP (eds) Ambiguity and Choice in Organizations. Universitetsforlaget, Bergen

O'Reilly CA III, Tushman ML (2011) Organizational Ambidextery in Action: How managers explore and exploit. Calif Manag Rev 53:5-22

O'Reilly CA III, Tushman ML (2013) Organizational Ambidextery: Past, present and future. Acad Manag Perspect 27:324-338

O'Reilly CA III, Harreld JB, Tushman ML (2009) Organizational Ambidexterity: IBM and emerging business opportunities. Calif Manag Rev 51:75-99

Orton JD (1997) From Inductive to Iterative Grounded Theory: Zipping the gap between process theory and process data. Scand J Manag 13:419-438

Pittaway L, Robertson M, Munir K, Denyer D, Neely A (2004) Networking and Innovation: A systematic review of the evidence. Int J Manag Rev 5-6:137-168

Plowman DA, Solansky S, Beck TE, Baker L, Kulkarni M, Villareal Travis D (2007) The role of leadership in emergent, self-organization. The Leadership Quarterly, 18:341-356.

Ritter T, Gemünden HG (2003) Network Competence: Its impact on innovation success and its antecedents. J Bus Res 56:745-755

Ritter T, Gemünden HG (2004) The Impact of a Company's Business Strategy on its Technological Competence, Network Competence and Innovation Success. J Bus Res 57:548-556

Rossi F, Bertossi P, Gurisatti P, Sovieni L (2009) Incorporating a New Technology into Agent-Artifact Space: The case of control automation in Europe. In: Lane DA, van der Leeuw S, Pumain D, West G (eds) Complexity Perspectives in Innovation and Social Change. Springer Verlag, Berlin-Heidelberg

Sarasvathy SD, Dew N (2005) Entrepreneurial Logics for a Technology of Foolishness. Scand J Manag 21:385-406

Schrage M (2000) Serious Play. Harvard Business School Press, Cambridge (MA)

Sutton, RI (2001) The Weird Rules of Creativity. Harvard Business Review, September

Tushman ML, O'Reilly CA III (1996) Ambidextrous Organizations: Managing evolutionary and revolutionary change. Calif Manag Rev 38:8-30

Weick KE (1979) The Social Psychology of Organizing. Random House, New York

Weick KE (1995) Sensemaking in Organizations. Sage Publications, Thousand Oaks

Wired (1993) If Your Toaster Had a Brain. Wired, 01-01-1993. Available at <http://www.wired.com/1993/01/toaster>. Accessed on 18 March 2016. 